\title{
Covid-19: The time to shield all pregnant frontline workers is now
}

\author{
Recent outbreaks of influenza, Ebola, and Zika viruses have taught us that pregnant women are \\ uniquely vulnerable to emerging infectious threats. Let's not fail pregnant frontline workers during \\ the covid-19 pandemic, say Elizabeth B Brickley and Enny S Paixão
}

\section{Elizabeth B Brickley assistant professor of infectious disease epidemiology, Enny S Paixão}

London School of Hygiene and Tropical Medicine, UK

Last month the Royal College of Obstetricians and Gynaecologists introduced new guidance ${ }^{1}$ on covid-19 and occupational health, asserting that for pregnant healthcare workers after 28 weeks' gestation and those with underlying health conditions "a more precautionary approach is advised. Women in this category should be recommended to stay at home." This precautionary approach should be extended to all pregnant workers on the frontline of the covid-19 response, including those in non-medical roles.

To accommodate and protect the developing fetus, pregnancy exerts new pressures on a woman's respiratory and cardiovascular systems and induces profound changes to her immune system. Pregnant women are at increased risk during gestation of developing hypertension and diabetes, both newly recognised risk factors for severe covid- $19 .{ }^{2}$ Compared with their non-pregnant peers, pregnant women may also have markedly altered immune responses when they encounter new infectious agents like the novel severe acute respiratory syndrome coronavirus (SARS-CoV-2) that causes covid-19.

Few pregnant women have had confirmed cases of covid-19 to date, and the evidence base on the consequences of SARS-CoV-2 infection in pregnancy ${ }^{3}$ is scant. Vital comparisons of the clinical course of covid- $19^{4}$ between pregnant and non-pregnant women of child bearing age are, unfortunately, lacking. Vertical transmission remains an open question. The relative risks of adverse pregnancy outcomes, including miscarriages, intrauterine growth restrictions, stillbirths, congenital anomalies, and preterm births, between SARS-CoV-2 infected and uninfected pregnant women are also unknown.

Looking back to recent emerging infectious disease outbreaks, we have good reasons to be concerned about pregnant frontline professionals.

Past outbreaks teach us that pregnant women may be at heightened risk of severe complications from respiratory infections. In 2009, a pandemic strain of influenza A (H1N1) emerged and rapidly spread across the globe. When researchers collated 120 studies investigating the risks of influenza A (H1N1)pdm09 in pregnancy, ${ }^{5}$ they concluded that infections were associated with higher risks of hospitalisation, intensive care admission, and death. Further evidence, from both the $2009^{6}$ and $1918^{7}$ pandemics, indicates that infection with influenza during the first trimester is associated with increased risks of fetal loss. Analogous reports of severe pregnancy complications and fetal demise can also be found in the more limited literature on the coronaviruses that caused epidemics of $\mathrm{SARS}^{8}$ and MERS. $^{9}$

Past outbreaks also show us that, despite facing disproportionately high risks, pregnant women may be systematically excluded from trials of potentially lifesaving vaccines and therapeutics. Consider, for example, the 2013-16 Ebola outbreak in Guinea, Liberia, and Sierra Leone. Observational reports dating back to $1976^{10}$ suggest that Ebola and pregnancy may be a deadly combination: over $80 \%$ of infected pregnant women die and virtually all lose their pregnancies. Nevertheless, when investigators examined the clinical trials of vaccines and drugs "proposed, initiated, or conducted" during the recent Ebola virus outbreak in west Africa, they found that all 14 trials failed to include pregnant women. ${ }^{11}$ Much hope is currently pinned on the development of a vaccine for SARS-CoV-2, but it remains uncertain to what extent such a vaccine would benefit pregnant women.

Finally, past outbreaks illustrate the devastating costs of delays in protecting pregnant women. The 2015-17 Zika virus outbreak and the ensuing epidemic of children born with microcephaly and other congenital birth defects provide perhaps the most striking example of the potential dangers of failing to shield pregnant women from emerging viral threats.

After the cluster of microcephaly was first recognised in north east Brazil, epidemiologists swiftly made the causal connection to the seemingly benign Zika virus ${ }^{12}$ and recognised the elevated risks of infection during the first trimester. ${ }^{13}$ For many women, the evidence came too late. Although there are currently no reports of birth defects associated with SARS-CoV-2, case 
reports by Dong et $\mathrm{al}^{14}$ and Zeng et $\mathrm{al}^{15}$ of three neonates born with elevated IgM antibodies to the virus have raised new concerns of the possibility of congenital infection.

The covid-19 pandemic has only been unfolding for five months, and the full impact of SARS-CoV-2 infections during pregnancy is yet to be seen. Nevertheless, the lack of evidence is not a reason to wait before we act. Pregnancy is a unique, but fleeting, season of many women's lives. In this unprecedented public health crisis, we can afford to offer pregnant workers in essential public service roles the opportunity to step back temporarily from their frontline professional duties. Failing to adopt protective measures now could place pregnant women and their offspring at unnecessary risk.

Government officials around the world should act today to shield all pregnant frontline workers from exposure to covid-19. We need to respect pregnant women's autonomy to choose whether to continue working during the pandemic. We should provide pregnant workers in conventionally public facing roles with alternative means to contribute, such as through teleworking opportunities. When that is not possible, we must ensure pregnant workers, regardless of gestational stage, have the option of a viable temporary off-ramp from professional duties, comprising an early paid maternity leave with stable healthcare coverage, and a clear path to career re-entry.

EBB receives support from the European Union's Horizon 2020 research and innovation programme under ZikaPLAN grant agreement number 734584 and the Wellcome Trust and the UK Department for International Development (205377/Z/16/Z). ESP is funded by the Wellcome Trust (grant number 213589/Z/18/Z).

Competing interests: None declared.
1 Royal College of Obstetricians and Gynaecologists. Covid-19 virus infection and pregnancy. 21 April 2020. www.rcog.org.uk/globalassets/documents/guidelines/2020-04-21occupational-health-advice-for-employers-and-pregnant-women.pdf

2 Guan WJ, Ni ZY, Hu Y, et alChina Medical Treatment Expert Group for Covid-19. Clinical characteristics of coronavirus disease 2019 in China. N Engl J Med 2020;382:1708-20. 10.1056/NEJMoa2002032 32109013

3 Della Gatta AN, Rizzo R, Pilu G, Simonazzi G. Covid-19 during pregnancy: a systematic review pf reported cases. Am J Obstet Gynecol2020 Apr 17. Pii:S0002-9378(20)30438-5.

4 Chen L, Li Q, Zheng D, et al. Clinical characteristics of pregnant women with covid-19 in Wuhan, China. N Engl J Med 2020. 10.1056/NEJMc2009226. 32302077

5 Mosby LG, Rasmussen SA, Jamieson DJ. 2009 pandemic influenza A (H1N1) in pregnancy: a systematic review of the literature. Am J Obstet Gynecol 2011;205:10-8. 10.1016/j.ajog.2010.12.033 21345415

6 Gunnes N, Gjessing HK, Bakken IJ, et al. Seasonal and pandemic influenza during pregnancy and risk of fetal death: A Norwegian registry-based cohort study. Eur $J$ Epidemiol 2020. 10.1007/s10654-020-00600-z. 31950373

7 Bloom-Feshbach K, Simonsen L, Viboud C, et al. Natality decline and miscarriages associated with the 1918 influenza pandemic: the Scandinavian and United States experiences. J Infect Dis 2011;204:1157-64. 10.1093/infdis/jir510 21917887

8 Wong SF, Chow KM, Leung TN, et al. Pregnancy and perinatal outcomes of women with severe acute respiratory syndrome. Am J Obstet Gynecol 2004;191:292-7. 10.1016/j.ajog.2003.11.019 15295381

9 Alfaraj SH, Al-Tawfiq JA, Memish ZA. Middle East Respiratory Syndrome Coronavirus (MERS-CoV) infection during pregnancy: Report of two cases \& review of the literature. J Microbiol Immunol Infect 2019;52:501-3. 10.1016/j.jmii.2018.04.005 29907538

10 Bebell LM, Oduyebo T, Riley LE. Ebola virus disease and pregnancy: A review of the current knowledge of Ebola virus pathogenesis, maternal, and neonatal outcomes. Birth Defects Res 2017;109:353-62. 10.1002/bdra.23558 28398679

11 Gomes MF, de la Fuente-Núñez V, Saxena A, Kuesel AC. Protected to death: systematic exclusion of pregnant women from Ebola virus disease trials. Reprod Health 2017;14(Suppl 3):172. 10.1186/s12978-017-0430-2 29297366

12 de Araújo TVB, Ximenes RAA, Miranda-Filho DB, etal. investigators from the Microcephaly Epidemic Research GroupBrazilian Ministry of HealthPan American Health

OrganizationInstituto de Medicina Integral Professor Fernando FigueiraState Health Department of Pernambuco. Association between microcephaly, Zika virus infection, and other risk factors in Brazil: final report of a case-control study. Lancet Infect Dis 2018;18:328-36. 10.1016/S1473-3099(17)30727-2 29242091

13 Brasil P, Pereira JPJr, Moreira ME, et al. Zika virus infection in pregnant women in Rio de Janeiro. N Engl J Med 2016:375:2321-34. 10.1056/NEJMoa1602412 26943629

14 Dong L, Tian J, He S, et al. Possible vertical transmission of SARS-CoV-2 from an infected mother to her newborn. JAMA 2020. 10.1001/jama.2020.4621. 32215581

15 Zeng H, Xu C, Fan J, et al. Antibodies in infants born to mothers with covid-19 pneumonia. JAMA 2020. 10.1001/jama.2020.4861. 32215589

Published by the BMJ Publishing Group Limited. For permission to use (where not already granted under a licence) please go to http://group.bmj.com/group/rights-licensing/ permissions 